\title{
Strain-specific steroidal control of pituitary function
}

\author{
Sang-Nam Lee, Bonnie Peng ${ }^{1}$, Roxane Desjardins ${ }^{2}$, John E Pintar ${ }^{1}$, Robert Day ${ }^{2}$ and Iris Lindberg \\ Department of Biochemistry and Molecular Biology, Louisiana State University Health Sciences Center, New Orleans, 1901 Perdido Street, New Orleans, \\ Louisiana 70112, USA \\ ${ }^{1}$ Department of Neuroscience and Cell Biology, University of Medicine and Dentistry of NJ, Piscataway, New Jersey 08854, USA \\ ${ }^{2}$ Département de Pharmacologie, Faculté de Mèdecine et Institut de Pharmacologie de Sherbrooke, Université de Sherbrooke, Québec, Canada JIH 5N4 \\ (Requests for offprints should be addressed to I Lindberg; Email: ilindb@Isuhsc.edu)
}

\begin{abstract}
We have previously shown that 7B2 null mice on the $129 / \mathrm{SvEvTac}$ (129) genetic background die at 5 weeks of age with hypercorticosteronemia due to a Cushing's-like disease unless they are rescued by adrenalectomy; however, 7B2 nulls on the C57BL/6NTac (B6) background remain healthy, with normal steroid levels. Since background exerts such a profound influence on the phenotype of this mutation, we have evaluated whether these two different mouse strains respond differently to high circulating steroids by chronically treating wild-type 129 and B6 mice with the synthetic steroid dexamethasone (Dex). Dex treatment decreased the dopamine content of the neurointermediate lobes (NIL) of 129 mice, leading to NIL enlargement and increased total $D_{2} R$ mRNA in the 129, but not the B6, NIL. Despite the decrease in this inhibitory transmitter, Dex-treated 129 mice exhibited reduced circulating $\alpha$-melanocyte-stimulating hormone
\end{abstract}

$(\boldsymbol{\alpha}-\mathrm{MSH})$ along with reduced POMC-derived peptides compared with controls, possibly due to reduced POMC content in the NIL. In contrast, Dex-treated B6 mice showed lowered cellular ACTH, unchanged $\alpha-\mathrm{MSH}$ and $\beta$-endorphin, and increased circulating $\alpha-\mathrm{MSH}$, most likely due to increased cleavage of NIL ACTH by increased PC2. Dextreated 129 mice exhibited hyperinsulinemia and lowered blood glucose, whereas Dex-treated B6 mice showed slightly increased glucose levels despite their considerably increased insulin levels. Taken together, our results suggest that the endocrinological response of 129 mice to chronic Dex treatment is very different from that of B6 mice. These straindependent differences in steroid sensitivity must be taken into account when comparing different lines of transgenic or knockout mice.

Journal of Endocrinology (2007) 192, 515-525

\section{Introduction}

Prohormone convertase 1 (PC1/3) along with prohormone convertase 2 (PC2), members of the family of calciumdependent subtilisin-like endoproteases, is predominantly expressed in neuronal and endocrine cells (Seidah et al. 1990, Day et al. 1992). Both PC1/3 and PC2 generate bioactive peptides from prohormones such as proopiomelanocortin (POMC; Benjannet et al. 1991), proglucagon (Rouille et al. 1997), and proinsulin (Bennett et al. 1992) by endoproteolytic processing at paired basic residues (reviewed by Seidah et al. 1994). PC 2 and PC1/3 are both synthesized as proenzymes; the propeptide must be cleaved to generate an enzymatically active mature species (Muller \& Lindberg 1999). Unlike PC1/3, the PC2 precursor requires a neuroendocrine-binding partner, $7 \mathrm{~B} 2$, in order to generate an active enzyme molecule (Muller et al. 1997, Muller \& Lindberg 1999). While the molecular mechanism of the $\mathrm{PC} 2$ and $7 \mathrm{~B} 2$ interaction remains unclear, three subdomains within proPC2 and a 36-residue peptide within 7B2 are known to participate (Muller et al. 1999), and our present working hypothesis is that $7 \mathrm{~B} 2$ blocks proPC2 from assuming a non-activatable conformer (S-N Lee \& I Lindberg, unpublished data).

The POMC precursor is expressed in both the corticotrophs of the anterior lobe (AL) and the melanotrophs of the pituitary neurointermediate lobe (NIL). However, corticotrophs express mainly PC1 mRNA with low levels of PC2 mRNA, while melanotrophs express high levels of PC2 mRNA with appreciable PC1 mRNA levels (Seidah et al. 1990, Day et al. 1992). Since the specificity of PC1/3 and PC2 is not identical, processing of the POMC precursor differs greatly between corticotrophs and melanotrophs (Mains \& Eipper 2000). In AL corticotrophs, POMC is processed mainly into adreno-corticotropic hormone (ACTH) and $\beta$-lipotropin as well as into lesser amounts of $\beta$-endorphin, while in NIL melanotrophs, POMC-derived peptides are cleaved to a variety of smaller bioactive peptides, such as $\alpha$-melanocytestimulating hormone $(\alpha-\mathrm{MSH})$ and $\beta$-endorphin (Mains \& Eipper 2000). Secretion of POMC-derived peptides in both cell types is stimulated by both the hypothalamic peptides, arginine vasopressin and corticotropin-releasing factor (CRF; Vale et al. 1981, Lundblad \& Roberts 1988). Control of 
expression and secretion of POMC-derived peptides is negatively regulated in a cell type-dependent manner; in the AL, glucocorticoids exert a negative feedback effect by a direct action on corticotrophs (Raymond et al. 1979) and by inhibiting hypothalamic CRF (Suda et al. 1984). By contrast, in the NIL, POMC expression and secretion are primarily under direct tonic inhibitory control by A14 periventricularhypophysial dopaminergic neurons (Goudreau et al. 1995). In vivo chronic administration with $\mathrm{D}_{2} \mathrm{R}$ agonists decreases melanotroph POMC biosynthesis, the secretion of $\alpha-\mathrm{MSH}$ and $\beta$-endorphin (Chen et al. 1983, Beaulieu et al. 1984), and the melanotroph proliferation rate (Chronwall et al. 1987). In addition, removal of dopaminergic axons within the rat intermediate lobe by the administration of 6-hydroxydopamine increases melanotroph proliferation (Rychter \& Stepien 1977, Gary \& Chronwall 1992). Thus, POMC expression is controlled differently in the two lobes of the pituitary.

Previous data obtained using the PC2 and 7B2 null mouse models have shown that both nulls show defective prohormone processing in vivo (Furuta et al. 1998, Westphal et al. 1999, Laurent et al. 2002). Interestingly, PC2 and 7B2 null mice exhibit exceedingly different phenotypes; PC2 null mice are healthy except for slight hypoglycemia and runting (Furuta et al. 1997), while 7B2 null mice die at 5 weeks due to a Cushing's disease-like disorder (Westphal et al. 1999). Cushing's disease normally arises from adrenal hypercorticosteronism as a result of ACTH hypersecretion from anterior pituitary (reviewed by Shomali \& Hussain 2000); the 7B2 null instead develops a Cushing's-like disease via greatly enhanced secretion of ACTH from the NIL (Westphal et al. 1999). Hypercorticosteronism is directly involved in the lethal phenotype, as adrenalectomy rescues the 7B2 129 null from death (Laurent et al. 2002).

However, the PC2 and 7B2 nulls were not generated on identical backgrounds; the PC2 nulls are in a mixed $129 \times \mathrm{B} 6$ background, while the 7B2 nulls are in a pure 129 genetic background. The profound effect of background on the 7B2 mutation was clearly demonstrated by transfer of the 7B2 null onto a pure $\mathrm{B} 6$ background, where it does not exhibit signs of disease (Peinado et al. 2005). Conversely, the movement of the PC2 null to a 129 background results in the development of illness similar to the 7B2 null after six generations of backbreeding (Peinado et al. 2005). Since ACTH hypersecretion and hypercorticosteronism have been directly implicated in the development of illness, we speculated that the two strains are differentially sensitive to ACTH and steroids. Indeed, we have confirmed that 129 mice possess a more sensitive adrenocortical response to ACTH than B6 mice using ACTH challenge experiments (Peinado et al. 2005).

In order to test for other strain-dependent effects of excess circulating steroids, in this study we have treated wild-type 129 and B6 mice with chronic dexamethasone (Dex) to reproduce the effect of excess circulating steroid in a manner similar to that observed in 7B2 nulls. Dex is a potent synthetic corticosteroid that mimics the action of endogenous steroids in the suppression of $\mathrm{AL} \mathrm{ACTH}$ synthesis and secretion (Murphy 1991). We have examined the effect of Dex on the hypothalamo-pituitary-adrenal (HPA) axis in both 129 and B6 wild-type mice and determined cellular and/or circulating plasma levels of ACTH, $\alpha$-MSH, $\beta$-endorphin, dopamine, and insulin using RIA, and blood glucose levels. Lastly, we have performed ultrastructural analyses of melanotrophs and in situ hybridization of $\mathrm{D}_{2} \mathrm{R}$ expression levels in NIL. Our results, described below, reveal considerable strain differences in the response to steroids in most of the parameters measured.

\section{Materials and Methods}

\section{Animals}

Four-week-old 129/SvEvTac and C57BL/6NTac wild type (WT) males were commercially purchased from Taconic Farms (Germantown, NY, USA). Mice were individually housed in an Association for Assessment and Accreditation of Laboratory Animal Care-approved animal care facility. Killing procedures were approved by the Louisiana State University Health Sciences Center (LSUHSC) animal care committee.

\section{Dexamethasone administration}

Four-week-old mice were given $10 \mu \mathrm{g} / \mathrm{ml}$ Dex (Sigma) in the drinking water for a week before they are killed; this timing was chosen to approximate the steroid susceptibility of the 129 7B2 null in the week prior to death. Pituitaries were removed and dissected into ALs and NILs. Separate lobes were individually homogenized via sonication either in $60 \mu \mathrm{l}$ $0.5 \mathrm{M} \mathrm{HClO}_{4}$ containing $10 \mathrm{mg} / \mathrm{ml}$ sodium bisulfite for dopamine assay or in $250 \mu \mathrm{l}$ ice-cold $5 \mathrm{M}$ acetic acid with $2 \mathrm{mg} / \mathrm{ml} \mathrm{BSA}$ for ACTH and $\alpha-\mathrm{MSH}$ assays. The samples were centrifuged for $15 \mathrm{~min}$ at $17383 \mathrm{~g}$ at $4{ }^{\circ} \mathrm{C}$ and then clear supernatants were individually harvested into fresh tubes. Serum was prepared from trunk blood obtained from mice killed by decapitation at the same time of the day (1030$1230 \mathrm{~h}$ ). Clotted blood was centrifuged briefly to separate the serum from cells and then collected individually in fresh tubes. All samples were stored frozen at $-70{ }^{\circ} \mathrm{C}$ until use.

\section{ACTH assays}

Ten to twenty microliters of a $1 / 200$ dilution of pituitary samples (ALs or NILs) or 50-100 $\mu 1$ sera prepared from either 129 control mice, Dex-treated 129 mice, B6 mice, or Dextreated B6 mice were assayed in duplicate using the two-site Nichols human $\mathrm{ACTH}_{1-39}$ assay kit (Nichols Institute, San Juan Capistrano, CA, USA). The ${ }^{125}$ I-ACTH antibody used in this kit is directed to both $\mathrm{N}$-terminal and C-terminal regions of intact ACTH molecule and does not recognize ACTH cleavage products. Dilutions were performed in RIA buffer $(100 \mathrm{mM}$ sodium phosphate, $\mathrm{pH} 7 \cdot 4$, containing $0 \cdot 1 \%$ heat-treated $\mathrm{BSA}, 50 \mathrm{mM} \mathrm{NaCl}$, and $0 \cdot 1 \%$ sodium azide). 
Radioactivity was determined using a Wallac 1470 Wizard gamma counter (Perkin-Elmer Life and Analytical Sciences, Shelton, CT, USA).

\section{Corticosterone assays}

Five to ten microliters of sera were assayed using the Immuchem Double Antibody corticosterone ${ }^{125}$ I RIA kit (M P Biomedicals, Orangeburg, NY, USA).

\section{$\alpha$-MSH and $\beta$-endorphin assays}

Twenty microliters (for ALs) or $10 \mu \mathrm{l}$ (for NILs) of a 1/200 dilution pituitary samples were subjected to assay in duplicate. The polyclonal anti- $\alpha-\mathrm{MSH}$ antiserum was commercially purchased from Chemicon (Temecula, CA, USA) and the polyclonal antiserum Bunny 3 (provided by Dr Robert Dores, University of Denver, Denver, CO, USA) was used to detect $\beta$-endorphin. ${ }^{125}$ I-Labeled $\alpha$-MSH and $\beta$-endorphin were prepared by the chloramine-T method, originally described by Hunter \& Greenwood (1962). RIAs were carried out according to protocols described previously (Fortenberry et al. 1999). Samples were incubated with 10000 c.p.m. iodinated peptide and the appropriate dilution of rabbit antiserum in a final volume of $300 \mu \mathrm{l}$ at $4{ }^{\circ} \mathrm{C}$ overnight. To separate the antibodybound labeled peptide from the unbound labeled peptide, $1 \mathrm{ml}$ $25 \%$ polyethylene glycol and $100 \mu \mathrm{l} 7 \cdot 5 \%$ carrier bovine $\gamma$-globulin (in PBS) were added. The samples were vortexed, kept on ice for $30 \mathrm{~min}$, and then centrifuged for $20 \mathrm{~min}$ at $3000 \mathrm{~g}$ at $4{ }^{\circ} \mathrm{C}$ using a Sorvall RT6000B refrigerated centrifuge. The supernatant was aspirated and the radioactivity in the pellets was determined. For serum samples, $100 \mu \mathrm{l}$ sera were assayed in duplicate using the EURIA- $\alpha$-MSH RIA kit (Alpco Diagnostics, Windham, NH, USA). This anti- $\alpha-\mathrm{MSH}$-antiserum is directed toward the $\mathrm{C}$-terminal region of the $\alpha$-MSH molecule and does not recognize ACTH.

\section{Dopamine assays}

Ten microliters of AL or NIL samples were assayed in duplicate using a dopamine RIA kit (Rocky Mountain Diagnostics, Colorado Springs, CO, USA).

\section{Glucose assays}

For glucose analyses, trunk blood collected from decapitated mice was analyzed immediately after killing, using a Freestyle blood glucose monitoring system (Therasense, Alameda, CA, USA).

\section{Insulin and glucagon assays}

Twenty-five microliters of sera (insulin assay) or 50-100 $\mu \mathrm{l}$ sera (glucagon assay) were assayed using the Linco RIA kit (St Charles, MI, USA).

\section{Western blotting}

All antisera were raised in rabbits against peptides conjugated to keyhole limpet hemocyanin. The antiserum against PC2 (LS18) was directed against the $\mathrm{COOH}$-terminus of mature PC2 (Shen et al. 1993). The antiserum against 7B2 (LS13) was raised against residues 23-39 of 7B2 (Zhu \& Lindberg 1995). The antiserum against PC1 (LS2) was directed against the amino terminus of mature PC1 (Vindrola \& Lindberg 1992, Zhu \& Lindberg 1995). The antiserum against POMC (LS41) was directed against ACTH(1-24) (Fortenberry et al. 2002). Thirty microliters of pituitary (ALs or NILs) samples solubilized directly in Laemmli sample buffer were applied to the gels. Samples were subjected to electrophoresis on $10 \%$ Criterion Tris- $\mathrm{HCl}$ (Bio-Rad) SDS gels, followed by western blotting using the respective antisera. Proteins were transferred from gels to nitrocellulose membranes, and the membranes were preincubated in 5\% non-fat milk in TBS for $30 \mathrm{~min}$ at room temperature prior to incubation overnight at $4{ }^{\circ} \mathrm{C}$ with antiserum 2B6 diluted 1:1000 in milk. Membranes were washed thrice with tris buffer saline (TBS) containing $0 \cdot 05 \%$ Tween followed by incubation at room temperature for $1.5 \mathrm{~h}$ with secondary antibody (goat anti-rabbit IgG coupled to alkaline phosphatase) diluted 1:10 000 in milk. Membranes were then washed once with TBS containing $0 \cdot 05 \%$ Tween and twice with TBS alone, and then developed with 5-bromo-4-chloro-3indolyl phosphate $p$-toluidine salt $/ p$-nitro blue tetrazolium chloride. For western blotting using horseradish peroxidase (HRP) conjugate as secondary antibody, membranes were incubated with SuperSignal West Pico chemiluminescent substrate (Pierce, Rockford, IL, USA) for $1 \mathrm{~min}$, and the chemiluminescent bands were revealed using a Fluor-S Max MultiImager System.

\section{In situ hybridization}

Pituitaries were removed, embedded in OCT compound (Miles, Elkhart, IN, USA), frozen in 2-methylbutane on dry ice powder, and stored at $-20^{\circ} \mathrm{C}$ before sectioning. Sections $(10 \mu \mathrm{m})$ were mounted onto Superfrost/Plus slides (Fisher Scientific, Fairlawn, NJ, USA) and stored at $70{ }^{\circ} \mathrm{C}$ until use.

The specific $\mathrm{D}_{2} \mathrm{R}$ complementary RNA and sense-strand control probes were transcribed using ${ }^{35}$ S-labeled UTP (New England Nuclear, Boston, MA, USA), Riboprobe System II transcription buffers (Promega), either T3 or T7 RNA polymerase (Stratagene, La Jolla, CA, USA), and a linearized plasmid construct that contains a $295 \mathrm{bp}$ cDNA fragment corresponding to the $\mathrm{D}_{2} \mathrm{R}$ exon 2 coding region.

In situ hybridization was performed as described by Snyder et al. (1998). Autoradiography was performed at $4{ }^{\circ} \mathrm{C}$ using a $1: 1$ dilution of Kodak NTB2 emulsion (Eastman Kodak) and HPLC grade $\mathrm{dH}_{2} \mathrm{O}$ for $1-4$ weeks. Eight slices were taken per pituitary and the density given represents 12 images from six sections. Densities (grains/area) were determined using NIH 1.62 image software. In all cases, hybridization with negative controls 
(sense-strand cRNA probes) in adjacent sections yielded only low background.

\section{Electron microscopy}

Sample preparation for electron microscopy was carried out using methods described previously (Day et al. 1987). Pituitaries from animals were removed, fixed in $2.5 \%$ glutaraldehyde in $0.05 \mathrm{M}$ sodium cacodylate buffer $(\mathrm{pH}$ 7.4), embedded in Epon, and sectioned. The sectioned samples were stained with $1 \%$ uranyl acetate and $6 \%$ lead citrate ( $\mathrm{pH} 10)$. Pictures of identical surface areas were taken at a magnification of $\times 7000$.

\section{Statistical analysis}

Data were analyzed using Student's $t$-test. Results are expressed as the mean \pm S.E.M. of the number of samples indicated.

\section{Results}

We treated 5-week-old 129 and B6 mice with the synthetic glucocorticoid Dex for 1 week, mimicking the effect of high circulating corticosteroid levels found in 7B2 nulls just prior to their death. Following dissection of the AL and NIL from whole pituitary, the levels of various pituitary and circulating hormones were determined. It was important to analyze the two pituitary lobes separately, given the fact that the release and content of POMC-derived peptides differs significantly between the two lobes. Most of the Dex-treated 129 animals showed symptoms of illness such as slower growth, fragile, thin skin, and poor hair coat condition. Dex-treated B6 mice showed similar, but much less severe signs of illness. Both 129 and B6 mice treated with Dex exhibited growth retardation compared with controls, as indicated by reduced body weights (Fig. 1). Although the volumes consumed by Dex-treated 129 mice were slightly more than other groups of mice, this effect did not reach statistical significance (Fig. 1).

Dex-treated 129 mice exhibit decreased circulating $\alpha-M S H$ levels, whereas Dex-treated B6 mice have increased circulating $\alpha$-MSH levels; basal hormone levels vary between the two strains

To assess a potential differential HPA axis response to chronically administered Dex, we assayed sera from Dextreated 129 and B6 animals for ACTH, corticosterone, and $\alpha-\mathrm{MSH}$ using radioimmunoassays.

The 129 control mice exhibited significantly (twofold) higher basal circulating levels of ACTH and fourfold higher circulating corticosterone than B6 mice (Table 1). Dex treatment decreased serum ACTH and corticosterone in both strains to undetectable levels (Table 1), a normal response of the HPA axis to glucocorticoid negative feedback inhibition (Suda et al. 1984).

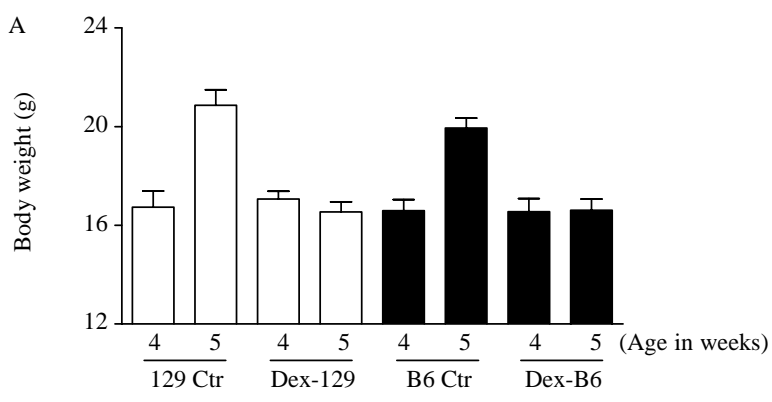

B

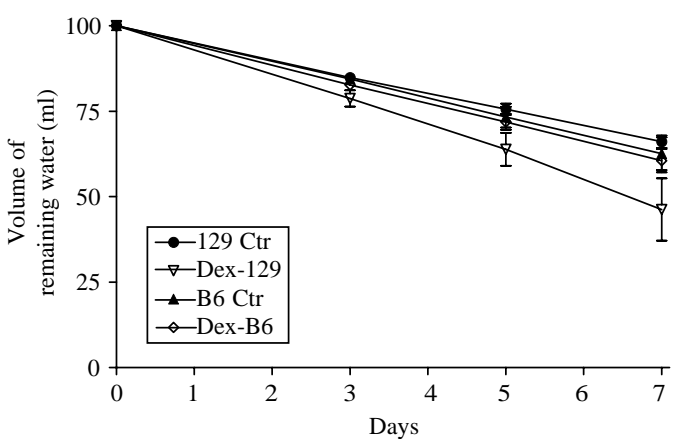

Figure 1 Dex-treated 129 and B6 mice show growth retardation (A) and no significant difference in water volumes drunk (B) $(P<0.6584 ; n=5)$. The 129 and B6 mice were given Dex in the drinking water for a week before killing. Ctr, control.

Circulating $\boldsymbol{\alpha}$-MSH levels were decreased approximately 2.5-fold in Dex-treated 129 mice when compared with their controls (Table 1). In contrast, Dex-treated B6 mice showed increased circulating $\alpha$-MSH levels (twofold) compared with controls (Table 1).

Dexamethasone treatment results in decreased ACTH, $\alpha-M S H$, $\beta$-endorphin, and POMC levels in 129 NIL

To test whether Dex treatment affects the pituitary contents of POMC-derived peptides, we performed RIAs of ACTH, $\alpha-\mathrm{MSH}$, and $\beta$-endorphin on pituitary lobe extracts; in addition, we performed western blotting for POMC, PC1, and PC2 in 129 and B6 NIL.

Although circulating ACTH levels in $129 \mathrm{WT}$ controls were higher than those in B6 WT mice (Table 1), AL ACTH levels were lower in 129 mice than in B6 mice, potentially indicating a higher secretion rate in 129 AL (Table 2). Dex treatment resulted in considerably decreased ACTH levels in the AL of both strains via the normal response of negative glucocorticoid feedback inhibition (Table 2). Additionally, $\beta$-endorphin was detected in B6 AL (Table 2), but not in 129 AL. This result indicates that the $\beta$-endorphin content of the B6 AL is considerably higher than that of the $129 \mathrm{AL}$ and confirms previous data on differential processing of POMC in different strains (Crabbe et al. 1981). 
Table 1 Comparison of the serum levels of ACTH, corticosterone, and $\alpha-M S H$ in 129 and B6 mice treated with dexamethasone or vehicle (Ctr). Data represent the mean \pm s.E.M. of the number of animals shown

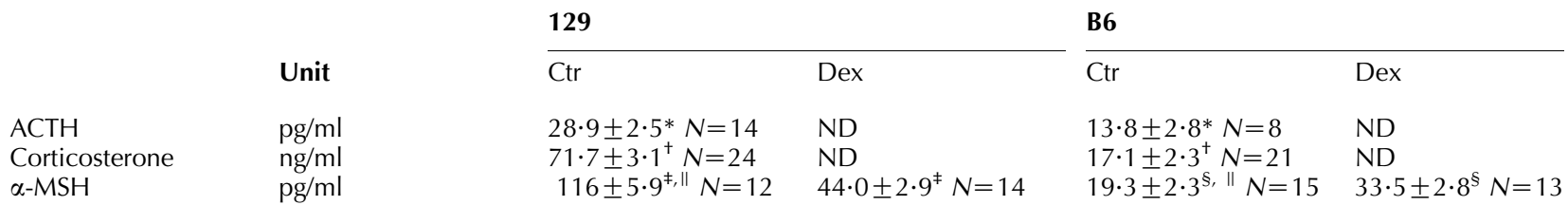

ND, not detectable (below the limit of detection, $1 \cdot 0 \mathrm{pg} / \mathrm{ml}$ for ACTH, $2 \cdot 5 \mathrm{ng} / \mathrm{ml}$ for corticosterone). *Significant statistical differences in ACTH levels were observed between $129 \mathrm{Ctr}$ and B6 Ctr mice $(P=0 \cdot 0012)$. ${ }^{+}$Significant statistical differences in corticosterone levels were observed between $129 \mathrm{Ctr}$ and B6 Ctr mice $(P<0 \cdot 0001) .{ }^{\ddagger}$, , Significant statistical differences in $\alpha-M S H$ levels were observed; ${ }^{\ddagger}$, between $\mathrm{Ctr}$ and Dex in 129 mice $(P<0 \cdot 0001) ;{ }^{\S}$, between $\mathrm{Ctr}$ and Dex in B6 mice $(P=0 \cdot 0005) ; "$, between $129 \mathrm{Ctr}$ and B6 Ctr mice $(P<0 \cdot 0001)$.

The basal content of ACTH in the 129 NIL was about 3.5-fold higher than that in the B6 NIL (Table 2). Although the circulating plasma $\boldsymbol{\alpha}$-MSH levels in 129 mice were sixfold higher than those in B6 mice (Table 1), there were no significant differences in both cellular $\alpha$-MSH and $\beta$-endorphin levels in the NIL of both strains (Table 2), supporting the idea of a higher basal peptide secretion rate from 129 NIL. As shown in Table 2, Dex treatment resulted in an unexpected alteration of POMC processing in the 129 NIL; a significant 1.4-, 2-, and 1.8-fold decrease in cellular ACTH, $\alpha-\mathrm{MSH}$, and $\beta$-endorphin levels respectively were observed. In contrast, ACTH levels in Dex-treated B6 NIL were decreased when compared with controls, and $\alpha$-MSH and $\beta$-endorphin levels were unaltered by Dex (Table 2).

Interestingly, the basal PC2 content of 129 NIL was significantly higher than that of B6 NIL in untreated mice, while no differences in PC1 content were observed between strains (Fig. 2A). This result suggests that the further processing of $\mathrm{ACTH}$ to $\boldsymbol{\alpha}-\mathrm{MSH}$ may be enhanced in 129 NIL compared with B6 NIL; this finding is in agreement with the considerably higher levels of basal plasma $\boldsymbol{\alpha}$-MSH observed in 129 mice. In addition, the total POMC contents were significantly higher in 129 mice than in B6 mice (Fig. 2B), possibly because the surface area of $129 \mathrm{NIL}$ is fourfold larger than that of B6 NIL (Fig. 3A).

In Dex-treated 129 NILs, the POMC content was decreased, and PC1 and PC2 contents were unaltered (Fig. 2). In Dex-treated 129 ALs, the contents of POMC and both enzymes were unaltered (data not shown). In contrast, Dex treatment resulted in significantly decreased POMC, but increased PC2 content in B6 NIL (Fig. 2), suggesting that in B6 mice, Dex treatment facilitates the processing of ACTH to $\alpha-\mathrm{MSH}$ via an increase in PC2.

Taken together with the RIA data presented in Table 1, these data imply that the decreased plasma $\boldsymbol{\alpha}$-MSH levels observed in Dex-treated 129 mice might result from the decreased POMC content in the NIL rather than via decreased release of $\alpha$-MSH. On the other hand, in B6 NIL, Dex may increase POMC processing by upregulating the content of the prohormone convertase PC2.

In summary, Dex treatment decreased both circulating (Table 1) and pituitary (Table 2) levels of POMC-derived peptides in 129 mice (similar to the results described in Chen et al. 1983), but many of these effects on POMC peptides were not recapitulated in B6 mice.

Table 2 Comparison of the pituitary levels of $\mathrm{ACTH}, \alpha-\mathrm{MSH}$, and $\beta$-endorphin ( $\mu \mathrm{g} /$ pituitary) in 129 and 129 mice treated with dexamethasone or vehicle (Ctr). Data represent the mean \pm S.E.M. of the number of animals shown

\begin{tabular}{|c|c|c|c|c|c|}
\hline & & \multicolumn{2}{|l|}{129} & \multicolumn{2}{|l|}{ B6 } \\
\hline & & $\mathrm{AL}$ & NIL & $\mathrm{AL}$ & NIL \\
\hline ACTH & $\begin{array}{l}\text { Ctr } \\
\text { Dex }\end{array}$ & $\begin{array}{l}0 \cdot 18 \pm 0 \cdot 012^{*} \neq N=11 \\
0 \cdot 04 \pm 0 \cdot 006^{*} N=12\end{array}$ & $\begin{array}{l}0 \cdot 07 \pm 0 \cdot 004^{\S,} N N=11 \\
0 \cdot 05 \pm 0.005^{\S,}, \mathrm{a} N=12\end{array}$ & $\begin{array}{l}0 \cdot 28 \pm 0 \cdot 016^{+,} \neq N=9 \\
0 \cdot 03 \pm 0 \cdot 002^{+} N=11\end{array}$ & $\begin{array}{l}0 \cdot 02 \pm 0 \cdot 003^{\|,}{ }^{\top} N=10 \\
0 \cdot 01 \pm 0 \cdot 002^{\|,} \text {a } N=15\end{array}$ \\
\hline$\alpha-\mathrm{MSH}$ & $\mathrm{Ctr}$ & ND & $0 \cdot 31 \pm 0.023^{b} N=15$ & ND & $0 \cdot 38 \pm 0 \cdot 038 N=13$ \\
\hline & Dex & ND & $0 \cdot 14 \pm 0 \cdot 016^{\mathrm{b}, \mathrm{c}} N=13$ & ND & $0 \cdot 33 \pm 0 \cdot 023^{\mathrm{C}} \quad N=11$ \\
\hline$\beta$-endorphin & $\begin{array}{l}\text { Ctr } \\
\text { Dex }\end{array}$ & $\begin{array}{l}\text { ND } \\
\text { ND }\end{array}$ & $\begin{array}{l}0 \cdot 92 \pm 0 \cdot 118^{\mathrm{d}} N=5 \\
0 \cdot 49 \pm 0 \cdot 081^{\mathrm{d}}, \mathrm{e} N=6\end{array}$ & $\begin{array}{l}0 \cdot 38 \pm 0 \cdot 088 N=5 \\
0 \cdot 24+0 \cdot 030 N=5\end{array}$ & $\begin{array}{l}1 \cdot 11 \pm 0 \cdot 103 \quad N=5 \\
1 \cdot 17 \pm 0.074^{\mathrm{e}} N=5\end{array}$ \\
\hline
\end{tabular}

\footnotetext{
ND, not detectable $(<0.05 \mu \mathrm{g} /$ pituitary). Significant statistical differences in the AL ACTH levels were observed; $*$, between Ctr and Dex of 129 mice $(P<0 \cdot 0001)$; ${ }^{\dagger}$, between $\mathrm{Ctr}$ and Dex of B6 mice $(P<0 \cdot 0001) ;{ }^{\ddagger}$, between $129 \mathrm{Ctr}$ and B6 Ctr mice $(P<0 \cdot 0001)$. Significant statistical differences in the NIL ACTH levels were observed; ${ }^{\S}$, between Ctr and Dex of 129 mice $(P=0 \cdot 0025) ; "$, between Ctr and Dex of B6 mice $(P=0 \cdot 0012) ;{ }^{\top}$, between $129 \mathrm{Ctr}$ and B6 Ctr mice $(P<0 \cdot 0001)$; ${ }^{\text {a }}$, between 129 Dex and B6 Dex mice $(P<0 \cdot 0001)$. Significant statistical differences in the NIL $\alpha-M S H$ levels were observed; ${ }^{\text {, }}$, between Ctr and Dex of 129 mice $(P<0 \cdot 0001) ;{ }^{c}$, between 129 Dex and B6 Dex mice $(P<0 \cdot 0001)$. Significant statistical differences in the NIL $\beta$-endorphin levels were observed; ${ }^{\mathrm{d}}$, between Ctr and Dex of 129 mice $(P=0 \cdot 0132)$; ${ }^{\text {, }}$, between 129 Dex and B6 Dex mice $(P=0 \cdot 0002)$.
} 

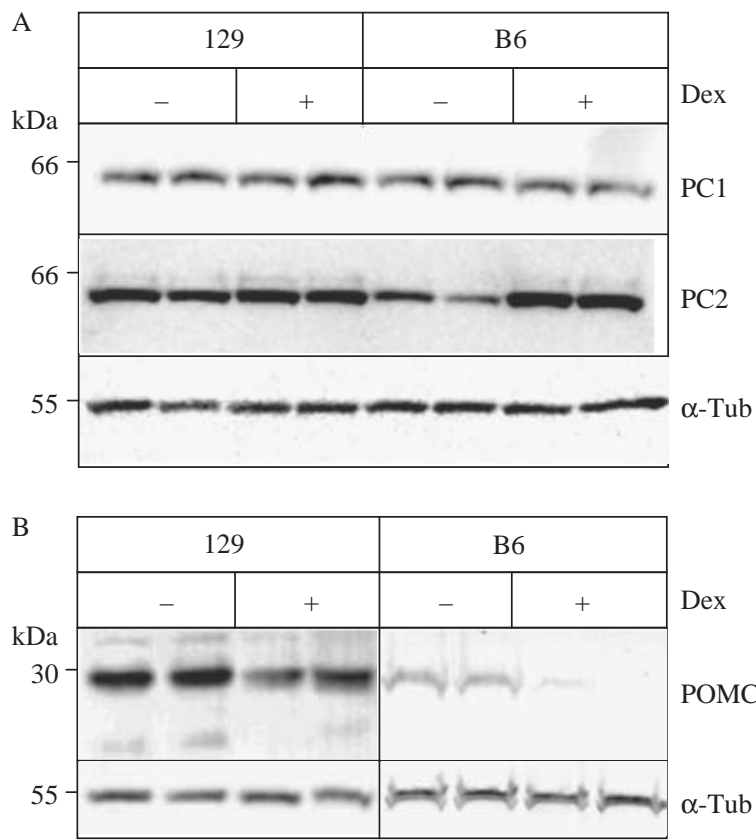

Figure 2 PC2 protein levels are increased when compared with their controls in Dex-treated B6 NIL, but not in Dex-treated 129 NIL (A). The NILs of both Dex-treated 129 and B6 mice contain reduced POMC levels (B). NIL lysates were analyzed by SDS-PAGE followed by western blotting using PC2 antiserum.

Dexamethasone administration decreases dopamine levels in 129 NIL and induces a prominent ER-Golgi complex in 129 melanotrophs; total $D_{2} R m R N A$ levels are slightly increased in Dex-treated 129 NIL

Interestingly, total NIL surface area was increased in Dextreated 129 NIL $(1 \cdot 5$-fold), indicating that 1 week of Dex administration causes melanotroph proliferation in 129 mice, but not in B6 mice (Fig. 3A). Since dopamine has a key role in the control of cell proliferation and in the maintenance of the melanotroph phenotype (Saiardi \& Borelli 1998), we determined total dopamine levels and $\mathrm{D}_{2} \mathrm{R}$ mRNA densities (grains per $\mu \mathrm{m}^{2}$ ) in the NILs of Dex-treated 129 and B6 mice using RIA and in situ hybridization respectively. In addition, we studied the morphological effect of Dex at the ultrastructural level using electron microscopy.

Basal dopamine levels in the NILs of 129 mice were significantly higher than those of B6 NILs (Fig. 3B), possibly due to the different sizes of the tissue in each strain (Fig. 3A). Dex treatment produced a lower dopaminergic tone in 129 NIL (1.3-fold), but not in B6 NIL (Fig. 3B), indicating differential steroid control. However, the dopamine level in the AL of both the strains of mice was unaltered following Dex treatment (data not shown). Since the synthesis and release of $\alpha$-MSH from the NIL are under inhibitory control by dopamine (Goudreau et al. 1995), these decreased dopamine levels in the Dex-treated 129 NIL would be expected to result in enhanced release and synthesis of
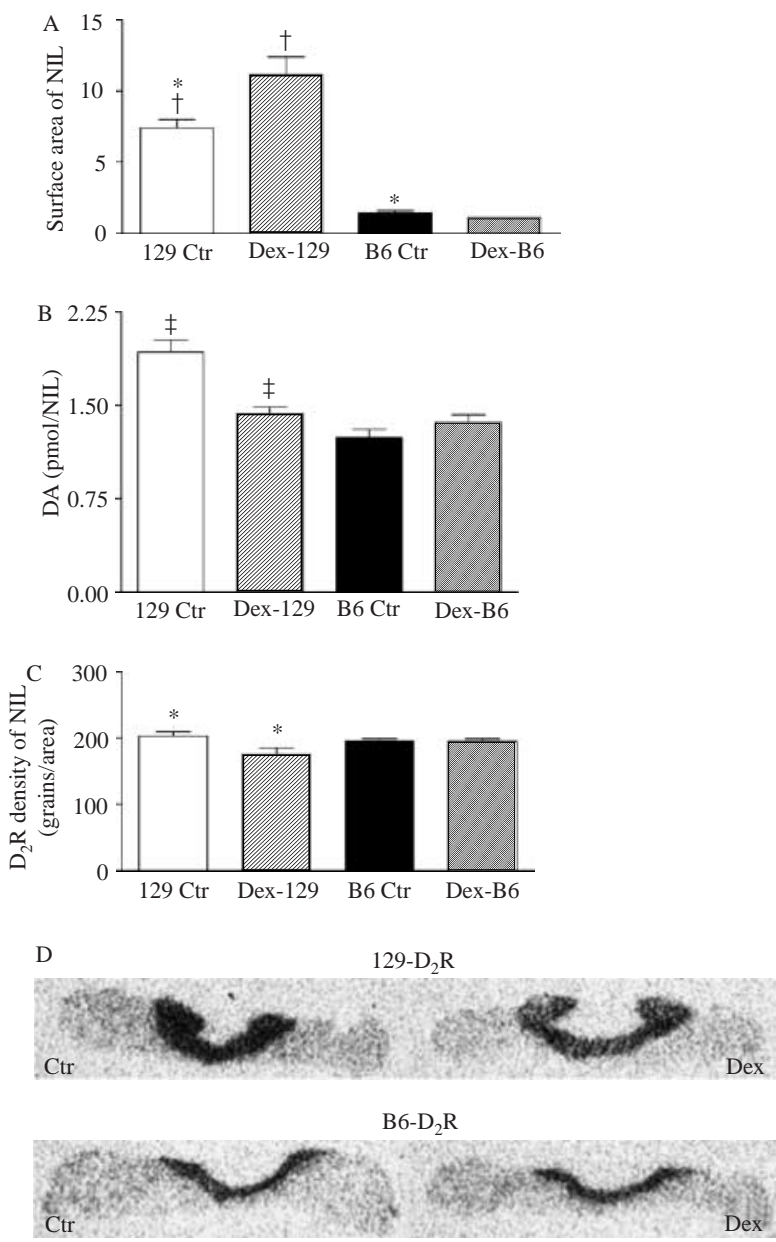

Figure 3 NIL dopamine levels are decreased in Dex-treated 129 mice. (A) The area volume (*significant differences between 129 and B6 NILs, $P<0 \cdot 0001 ;{ }^{\dagger}$ significant differences between Ctr and Dex-treated 129 NILs, $P<0 \cdot 0298$ ). (B) NIL $D_{2} R$ densities (grains per area) of Dex-treated 129 animals were decreased over their WT controls ( ${ }^{\ddagger} P<0 \cdot 0001 ; n=10$ ); however, total $D_{2} R$ mRNA levels in Dex-treated 129 NIL were slightly increased. (C) $D_{2} R$ density (*significant differences between Ctr and Dex-treated 129 NILs, $P=0 \cdot 0556$ ). (D) In situ hybridization of $\mathrm{D}_{2} \mathrm{R}$ mRNA.

$\boldsymbol{\alpha}$-MSH; this was clearly not the case (Table 1$)$. However, melanotrophs in Dex-treated 129 mice, but not in B6 mice, contained a prominent endoplasmic reticulum and Golgi complex, a phenotype associated with dopaminergic loss (Fig. 4; Gary \& Chronwall 1992, Chronwall et al. 1996).

Dex treatment resulted in a trend $(P=0.056)$ toward decreased $\mathrm{D}_{2} \mathrm{R}$ mRNA densities in 129 NIL, but not in B6 NIL (Fig. 3C). However, when the values of $\mathrm{D}_{2} \mathrm{R}$ mRNA densities are corrected for the larger sizes of Dex-treated 129 NILs $\left(1 \cdot 5\right.$-fold), increased total $\mathrm{D}_{2} \mathrm{R}$ mRNA contents $(1 \cdot 2-$ fold) are observed. This result is consistent with our finding of decreased dopamine levels in Dex-treated 129 NIL (Fig. 3B). In vivo chronic treatment with $\mathrm{D}_{2} \mathrm{R}$ antagonists is also known to increase $\mathrm{D}_{2} \mathrm{R}$ mRNA expression (Autelitano et al. 1989). 

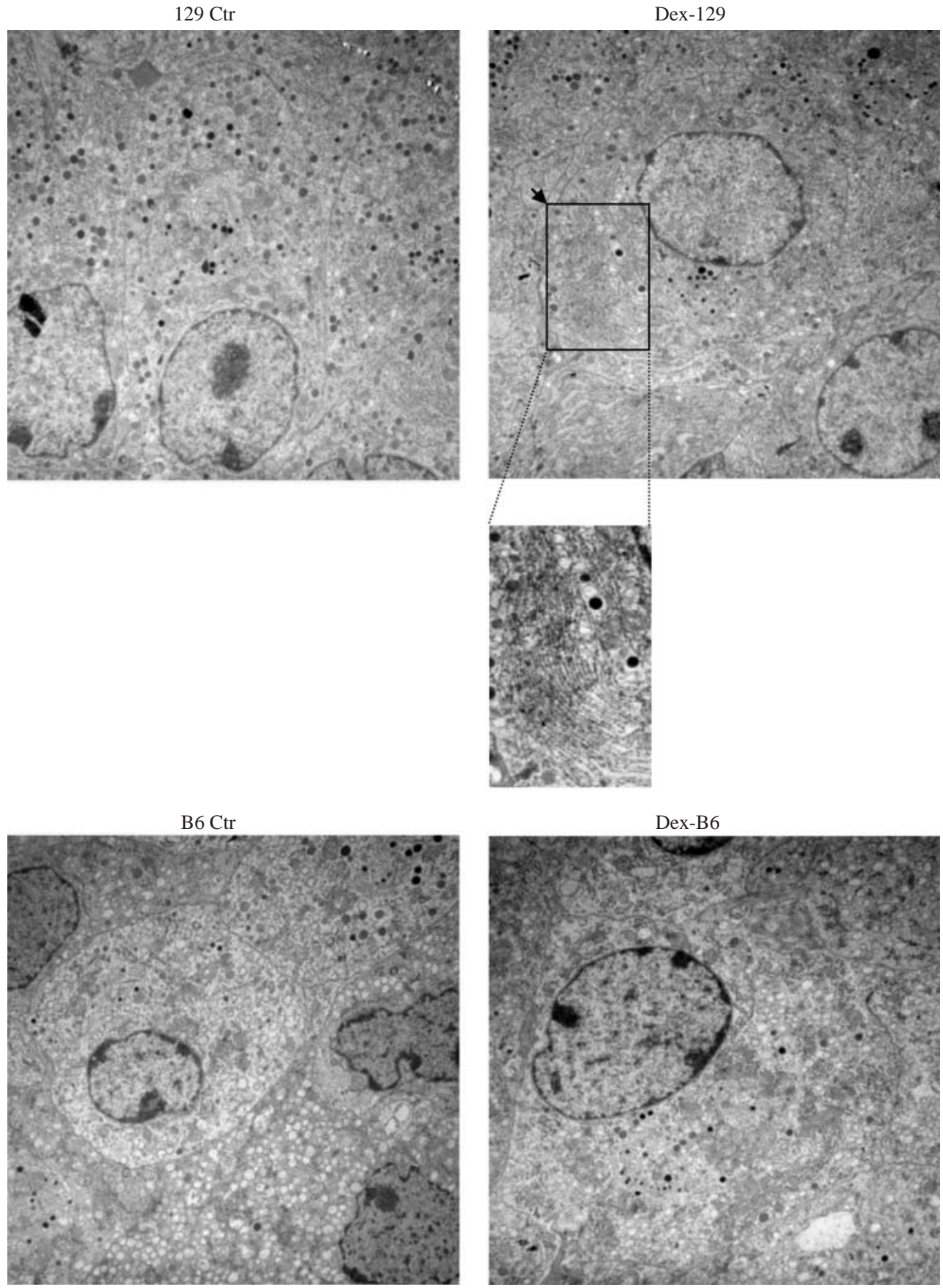

Figure 4 Dex-treated 129 melanotrophs show a prominent endoplasmic reticulum and Golgi complex (upper panel), while Dex-treated B6 melanotrophs do not differ from untreated controls at the ultrastructural level (lower panel). These data confirm the downregulation of dopaminergic control known to be associated with secretory membrane proliferation in 129 mice, but not in B6 mice. Inset, Image enlarged and enhanced by Corel Photo-Paint software.

Dexamethasone treatment of 129 animals results in considerably decreased glucose levels

We previously found that 7B2 nulls on the 129 background exhibit severe hypoglycemia; this contributes greatly to lethality (Sarac et al. 2002). In the work reported here, we observed that approximately $15 \%$ of the Dex-treated 129 mice unexpectedly died at about day 5 , while all B6 mice always survived Dex treatment. We determined serum glucose, 

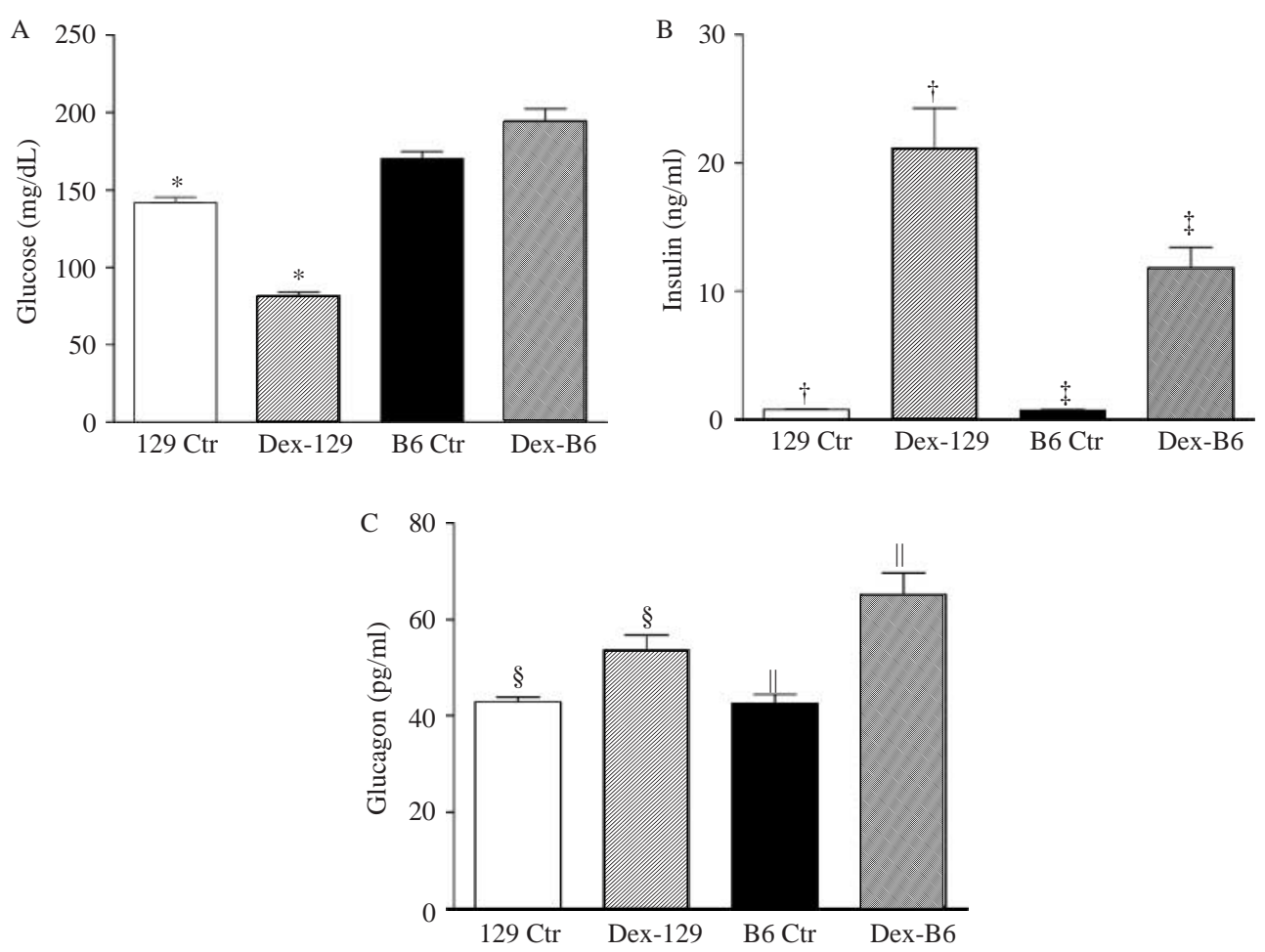

Figure 5 Dex-treated 129 animals exhibit lowered blood sugar levels and are hyperinsulinemic and hyperglucagonemic compared with their WT controls (Ctr). (A) Glucose levels (*significant differences between $\mathrm{Ctr}$ and Dex-treated 129 mice, $P<0 \cdot 0001$ ). (B) Insulin levels ( ${ }^{\dagger}$ significant differences between $\mathrm{Ctr}$ and Dex-treated 129 mice, $P<0 \cdot 0001$; ${ }^{\ddagger}$ significant differences between Ctr and Dex-treated B6 mice, $P<$ 0.0001). (C) Glucagon levels ( ${ }^{\S}$ significant differences between $\mathrm{Ctr}$ and Dex-treated 129 mice, $P=0 \cdot 0071$; "significant differences between Ctr and Dex-treated B6 mice, $P<0 \cdot 0001 ; n \geq 10$ ).

insulin, and glucagon levels in the surviving mice. Dex-treated 129 mice exhibited lowered blood sugar levels and strikingly elevated insulin levels, but only slightly increased levels of glucagon (Fig. 5). This result suggests that the lethality observed in Dex-treated 129 mice could occur, at least in part, due to considerably decreased glucose levels. In contrast, Dex treatment of B6 mice resulted in highly increased insulin and glucagon levels (Fig. 5); however, this did not result in lowered blood sugar levels, suggesting greater resilience and/or compensatory mechanisms in this strain.

\section{Discussion}

We have previously reported that the Cushing's disease-like symptoms generated by intermediate lobe ACTH hypersecretion and adrenal hypercorticosteronism in 7B2 nulls are heavily influenced by background (Peinado et al. 2005). In addition, we found that hypercorticosteronism is directly involved in the lethal phenotype of the 7B2 null, as adrenalectomy rescues this null from early death (Laurent et al. 2002). Since we observed a $3 \cdot 5$-fold drop in pituitary dopamine (an inhibitory transmitter controlling NIL peptide release) in $1297 \mathrm{~B} 2$ null mice, but not in $\mathrm{B} 67 \mathrm{~B} 2$ nulls, and since dopamine levels return to normal in adrenalectomized animals (Laurent et al. 2002), we hypothesized that steroids could somehow be involved in the dopaminergic disinhibition phenomenon, generating increased intermediate lobe peptide release. Further, this effect would have to occur in a strain-specific manner, since it does not occur in B6 7B2 nulls. This led us to the present investigation of potential differential strain effects of glucocorticoids on the HPA axis.

Dex treatment results in differential effects on pituitary dopamine and POMC processing in 129 and B6 mice

We observed that chronic Dex treatment indeed reduces pituitary dopamine in 129 mice, but not in B6 mice, upholding our previous results on strain-specific steroidal control of pituitary dopamine levels (Laurent et al. 2002). Interestingly, we observed a distinct enlargement of the NILs in Dex-treated 129 mice, accompanied by extensive rough endoplasmic reticulum and a prominent Golgi apparatus in melanotrophs. Earlier studies by others had shown that administration of $\mathrm{D}_{2} \mathrm{R}$ antagonists in vivo results in proliferation of melanotrophs. $\mathrm{D}_{2} \mathrm{R}$-deficient mice on the mixed $129 / \mathrm{Sv} \times \mathrm{C} 57 \mathrm{BL} / 6$ genetic background, with a $75 \%$ contribution of $\mathrm{C} 57 \mathrm{BL} / 6$ background, show enhanced 
melanotroph numbers (Saiardi \& Borelli 1998), and removal of dopaminergic axons by the administration of 6-hydroxydopamine results in an increase in melanotroph proliferation in rat pituitary intermediate lobe (Gary \& Chronwall 1992), linking downregulation of dopaminergic control to melanotroph proliferation. Therefore, the melanotroph proliferation exhibited by Dex-treated 129 mice is likely to be caused by the decrease in dopamine. It is interesting that these effects do not occur in B6 mice, a strain resistant to Dex-induced changes in dopamine.

Since dopamine is an inhibitory transmitter in the NIL, we hypothesized that the decreased dopaminergic tone generated by Dex treatment of 129 mice would result in increased circulating POMC-derived peptide levels; however, Dex treatment of 129 mice resulted in significantly decreased rather than increased circulating $\alpha-\mathrm{MSH}$, the intermediate lobe ACTH-derived peptide product in wild-type mice. Since Dex-treated 129 mice also exhibited reduced NIL POMC, $\alpha-M S H$, and $\beta$-endorphin levels, clearly Dex affects POMC synthesis in 129 NIL; if there is a Dex effect on NIL release, it is overshadowed by Dex effects on synthesis. Previous studies have shown that Dex treatment results in a reduction in NIL POMC mRNA in both intact and adrenalectomized rats (Roberts et al. 1982, Schachter et al. 1982). It has also been found that long-term Dex treatment of rats abolishes the haloperidol-induced increase in ir- $\beta$ endorphin, but further increases the haloperidol-induced rise in POMC mRNA (Autelitano et al. 1987), supporting the idea that circulating glucocorticoids can have complex and potent effects on NIL POMC expression and secretion.

The mechanism by which glucocorticoids can affect NIL POMC is not well understood. It has been demonstrated that the expression of GR in adult rat melanotropic cells is under negative dopaminergic control (Antakly et al. 1987). Schimchowitsch et al. (1994) reported the presence of functional GR, which negatively regulates melanotropic activity in the rabbit pituitary intermediate lobe. We performed western blotting to observe potentially induced changes in pituitary GR expression levels, but it proved impossible to detect any GR bands (data not shown). In situ hybridization analysis using PCR-amplified GR signals is needed to elucidate whether the reduction of dopamine levels has an effect on GR mRNA expression. In conclusion, since we could not recapitulate the NIL hypersecretion phenomenon using Dex treatment of wild-type mice, but did observe the expected dopamine decrease, the reduction in dopamine in the $1297 \mathrm{~B} 2$ null is unlikely to represent a primary cause of its NIL ACTH hypersecretion.

Dex treatment of B6 mice resulted in different cellular and circulating profiles of POMC-derived peptides when compared with 129 mice. While we also observed reduced NIL ACTH, $\alpha-\mathrm{MSH}$, and $\beta$-endorphin in this strain, dopamine levels were unaltered, and an increase in circulating $\alpha-\mathrm{MSH}$ was found. Interestingly, Dex treatment also resulted in significantly increased PC2 levels in the B6 (but not in the 129) NIL; since this enzyme is responsible for processing
ACTH to $\boldsymbol{\alpha}-\mathrm{MSH}$, this increase may directly explain the decreased tissue ACTH and increased circulating MSH levels. Other studies have shown that Dex treatment increases PC2 expression in the ocular ciliary epithelium (Ortego et al. 2002) and the endocrine cell line rMTC 6-23 (Barbero \& Kitabgi 1999). In contrast, the 129 NIL seemed to be fairly resistant to PC2 induction by Dex, indicating strain-specific differences in control of PC2 expression. In summary, the ability of Dex to control the synthesis and release of POMC-derived peptides in either the 129 or B6 NIL appears to occur directly through effects on POMC and PC2 expression rather than via dopaminergic mechanisms.

\section{Dex treatment uncovers strain differences in glucose regulation}

In addition to strain-dependent effects of Dex on pituitary peptides, we observed differences in glucose regulation. For example, Dex-treated 129 animals exhibited lowered blood sugar levels and highly increased insulin levels. In contrast, Dex-treated B6 animals, while also showing considerably increased insulin levels, had slightly increased glucose levels relative to controls. Recently, Goren et al. (2004) reported that male C57BL/6 animals are susceptible to glucose intolerance, which is associated with impaired insulin sensitivity in liver and fat tissues, whereas the liver and fat tissues from $129 \times 1$ animals exhibit greater insulin sensitivity than the same tissues from other strains. Therefore, the Dexinduced decrease in glucose levels in 129 mice might be due to strain-dependent insulin hypersensitivity, a hypothesis which requires testing through additional experiments. In addition, we observed that although insulin-induced hypoglycemia induces a rapid increase in plasma levels of hormones (glucagon, epinephrine, growth hormone, and cortisol) related to the glucose counterregulatory response (Cryer 1993), the increase in insulin was significantly higher in Dex-treated 129 mice when compared with Dex-treated B6 mice, while glucagon levels were lower in 129 mice after Dex treatment than in B6 mice. The lowered blood sugar levels seen in Dex-treated 129 mice support our previous data showing that older 7B2 nulls on the 129 background exhibit severe hypoglycemia, which contributes greatly to lethality (Sarac et al. 2002).

In conclusion, our study suggests that although both strains of mice can expand their insulin supply in response to increased Dex, only 129 mice exhibit glucocorticoid hypersensitivity, and these mice may consequently be more susceptible to the increased functional stress imposed by chronic corticosteronemia, resulting in their much greater morbidity when challenged with Dex administration. The exaggerated Dex response in 129 mice appears to be due to the failure of normal regulatory mechanisms, which modulate hormonal secretion and/or deficits in compensatory responses to impaired glucose homeostasis. In addition to the data showing that Dex-treated 129 NILs exhibit blunted inhibitory dopaminergic control of POMC expression and secretion, our results imply that the 129 mouse is already 
predisposed to Cushing's disease and Dex treatment induces further iatrogenic Cushing's disease. Therefore, we clearly demonstrate here that the lethal phenotype observed in 129 7B2 nulls (Laurent et al. 2002), but not in B6 7B2 nulls (Peinado et al. 2005), is caused by strain-dependent differences in steroid sensitivity. These considerable strain differences between 129 and B6 mice may provide a promising model system for studying steroidal effects on the HPA axis, and must certainly be taken into account when comparing the hormonal status of nulls constructed on different backgrounds.

\section{Acknowledgements}

We thank Gregory Hubbard and Jan Dufrene for assistance with animal handling. This work was supported by grants from NIDDK 49703 to I L, DA-08622 to J E P, and CIHR MOP-79283 and MOP-57870 to R D. The authors declare that there is no conflict of interest that would prejudice the impartiality of this scientific work.

\section{References}

Antakly T, Mercille S \& Cote JP 1987 Tissue-specific dopaminergic regulation of the glucocorticoid receptor in the rat pituitary. Endocrinology $1201558-1562$.

Autelitano DJ, Clements JA, Nikolaidis I, Canny BJ \& Funder JW 1987 Concomitant dopaminergic and glucocorticoid control of pituitary proopiomelanocortin messenger ribonucleic acid and beta-endorphin levels. Endocrinology 121 1689-1696.

Autelitano DJ, Snyder L, Sealfon SC \& Roberts JL 1989 Dopamine D2receptor messenger RNA is differentially regulated by dopaminergic agents in rat anterior and neurointermediate pituitary. Molecular and Cellular Endocrinology 67 101-105.

Barbero P \& Kitabgi P 1999 Protein 7B2 is essential for the targeting and activation of PC2 into the regulated secretory pathway of rMTC 6-23 cells. Biochemical and Biophysical Research Communications 257 473-479.

Beaulieu M, Goldman ME, Miyazaki K, Frey EA, Eskay RL, Kebabian JW \& Cote TE 1984 Bromocriptine-induced changes in the biochemistry, physiology, and histology of the intermediate lobe of the rat pituitary gland. Endocrinology 114 1871-1884.

Benjannet S, Rondeau N, Day R, Chretien M \& Seidah NG 1991 PC1 and PC2 are proprotein convertases capable of cleaving proopiomelanocortin at distinct pairs of basic residues. PNAS 88 3564-3568.

Bennett DL, Bailyes EM, Nielsen E, Guest PC, Rutherford NG, Arden SD \& Hutton JC 1992 Identification of the type 2 proinsulin processing endopeptidase as $\mathrm{PC} 2$, a member of the eukaryotic subtilisin family. Journal of Biological Chemistry 267 15229-15236.

Chen CL, Dionne FT \& Roberts JL 1983 Regulation of the pro-opiomelanocortin mRNA levels in rat pituitary by dopaminergic compounds. PNAS 80 2211-2215.

Chronwall BM, Millington WR, Griffen WS, Unnerstall JR \& O'Donohue TL 1987 Histological evaluation of the dopaminergic regulation of proopiomelanocortin gene expression in the intermediate lobe of the rat pituitary, involving in situ hybridization and $[3 \mathrm{H}]$ thymidine uptake. Endocrinology 120 1201-1211.

Chronwall BM, Sands SA, Dickerson DS, Sibley DR \& Gary KA 1996 Melanotrope dopamine D2 receptor isoform expression in the developing rat pituitary. International Journal of Developmental Neuroscience 14 77-86.
Crabbe JC Jr, Allen RG, Gaudette ND, Young ER, Kosobud A \& Stack J 1981 Strain differences in pituitary beta-endorphin and ACTH content in inbred mice. Brain Research 219 219-223.

Cryer PE 1993 Glucose counterregulation: prevention and correction of hypoglycemia in humans. American Journal of Physiology 264 E149-E155.

Day R, Lemaire S, Nadeau D, Keith I \& Lemaire I 1987 Changes in autacoid and neuropeptide contents of lung cells in asbestos-induced pulmonary fibrosis. American Review of Respiratory Disease 136 908-915.

Day R, Schafer MK, Watson SJ, Chretien M \& Seidah NG 1992 Distribution and regulation of the prohormone convertases PC1 and PC2 in the rat pituitary. Molecular Endocrinology 6 485-497.

Fortenberry Y, Liu J \& Lindberg I 1999 The role of the 7B2 CT peptide in the inhibition of prohormone convertase 2 in endocrine cell lines. Journal of Neurochemistry 73 994-1003.

Fortenberry Y, Hwang JR, Apletalina EV \& Lindberg I 2002 Functional characterization of ProSAAS: similarities and differences with 7B2. Journal of Biological Chemistry 277 5175-5186.

Furuta M, Yano H, Zhou A, Rouille Y, Holst JJ, Carroll R, Ravazzola M, Orci L, Furuta H \& Steiner DF 1997 Defective prohormone processing and altered pancreatic islet morphology in mice lacking active SPC2. PNAS 94 6646-6651.

Furuta M, Carroll R, Martin S, Swift HH, Ravazzola M, Orci L \& Steiner DF 1998 Incomplete processing of proinsulin to insulin accompanied by elevation of Des-31,32 proinsulin intermediates in islets of mice lacking active PC2. Journal of Biological Chemistry 273 1-7.

Gary KA \& Chronwall BM 1992 The onset of dopaminergic innervation during ontogeny decreases melanotrope proliferation in the rat pituitary intermediate lobe. International Journal of Developmental Neuroscience 10 131-142.

Goren HJ, Kulkarni RN \& Kahn CR 2004 Glucose homeostasis and tissue transcript content of insulin signaling intermediates in four inbred strains of mice: C57BL/6, C57BLKS/6, DBA/2, and 129X1. Endocrinology 145 3307-3323.

Goudreau JL, Falls WM, Lookingland KJ \& Moore KE 1995 Periventricularhypophysial dopaminergic neurons innervate the intermediate but not the neural lobe of the rat pituitary gland. Neuroendocrinology 62 147-154.

Hunter WM \& Greenwood FC 1962 Preparation of iodine-131 labelled human growth hormone of high specific activity. Nature 194 495-496.

Laurent V, Kimble A, Peng B, Zhu P, Pintar JE, Steiner DF \& Lindberg I 2002 Mortality in 7B2 null mice can be rescued by adrenalectomy: involvement of dopamine in ACTH hypersecretion. PNAS 99 3087-3092.

Lundblad JR \& Roberts JL 1988 Regulation of proopiomelanocortin gene expression in pituitary. International Journal of Developmental Neuroscience $\mathbf{9}$ 135-158.

Mains RE \& Eipper BA 2000 Proopiomelanocortin synthesis and cell-specific processing. In Handbook of Physiology, section 7: the Endocrine System, vol IV (ch V), pp 85-101. Oxford, UK: Oxford University Press.

Muller L \& Lindberg I 1999 The cell biology of the prohormone convertases PC1 and PC2. Progress in Nucleic Acids Research 63 69-108.

Muller L, Zhu X \& Lindberg I 1997 Mechanism of the facilitation of PC2 maturation by 7B2: involvement in ProPC2 transport and activation but not folding. Journal of Cell Biology 139 625-638.

Muller L, Zhu P, Juliano MA \& Lindberg I 1999 A 36-residue peptide contains all of the information required for 7B2-mediated activation of prohormone convertase 2. Journal of Biological Chemistry 274 21471-21477.

Murphy BE 1991 Treatment of major depression with steroid suppressive drugs. Journal of Steroid Biochemistry and Molecular Biology 39 239-244.

Ortego J, Wollmann G \& Coca-Prados M 2002 Differential regulation of gene expression of neurotensin and prohormone convertases PC1 and PC2 in the bovine ocular ciliary epithelium: possible implications on neurotensin processing. Neuroscience Letters $33349-53$.

Peinado JR, Laurent V, Lee SN, Peng BW, Pintar JE, Steiner DF \& Lindberg I 2005 Strain-dependent influences on the hypothalamo-pituitary-adrenal axis profoundly affect the 7B2 and PC2 null phenotypes. Endocrinology 146 3438-3444.

Raymond V, Lepine J, Lissitzky JC, Cote J \& Labrie F 1979 Parallel release of ACTH, beta-endorphin, alpha-MSH and beta-MSH-like immunoreactivities in rat anterior pituitary cells in culture. Molecular and Cellular Endocrinology 16 113-122. 
Roberts JL, Chen CL, Eberwine JH, Evinger MJ, Gee C, Herbert E \& Schachter BS 1982 Glucocorticoid regulation of proopiomelanocortin gene expression in rodent pituitary. Recent Progress in Hormone Research 38 227-256.

Rouille Y, Bianchi M, Irminger JC \& Halban PA 1997 Role of prohormone convertase PC2 in the processing of proglucagon to glucagon. FEBS Letters 413 119-123.

Rychter J \& Stepien H 1977 Effects of pimozide and bromocriptine on the proliferation of rat pituitary pars intermedia cells. Journal of Endocrinology 75 443-444.

Saiardi A \& Borelli E 1998 Absence of dopaminergic control on melanotrophs leads to Cushing's-like syndrome in mice. Molecular Endocrinology 12 1133-1139.

Sarac MS, Zieske AW \& Lindberg I 2002 The lethal form of Cushing's in 7B2 null mice is caused by multiple metabolic and hormonal abnormalities. Endocrinology 143 2324-2332.

Schachter BS, Johnson LK, Baxter JD \& Roberts JL 1982 Differential regulation by glucocorticoids of proopiomelanocortin mRNA levels in the anterior and intermediate lobes of the rat pituitary. Endocrinology $1101442-1444$.

Schimchowitsch S, Plante M, Kienlen P, Felix JM, Koch B \& Stoeckel ME 1994 Glucocorticoids, but not dopamine, negatively regulate the melanotrophic activity of the rabbit pituitary intermediate lobe. Journal of Neuroendocrinology 6 385-390.

Seidah NG, Gaspar L, Mion P, Marcinkiewicz M, Mbikay M \& Chretien M 1990 cDNA sequence of two distinct pituitary proteins homologous to Kex2 and furin gene products: tissue-specific mRNAs encoding candidates for pro- hormone processing proteinases. DNA and Cell Biology 9789.

Seidah NG, Chretien M \& Day R 1994 The family of subtilisin/kexin like pro-protein and pro-hormone convertases: divergent or shared functions. Biochimie 76 197-209.
Shen FS, Seidah NG \& Lindberg I 1993 Biosynthesis of the prohormone convertase PC2 in Chinese hamster ovary cells and in rat insulinoma cells. Journal of Biological Chemistry 268 24910-24915.

Snyder SE, Pintar JE \& Salton SR 1998 Developmental expression of VGF mRNA in the prenatal and postnatal rat. Journal of Comparative Neurology 394 64-90.

Suda T, Tomori N, Tozawa F, Mouri T, Demura H \& Shizume K 1984 Effect of dexamethasone on immunoreactive corticotropin-releasing factor in the rat median eminence and intermediate-posterior pituitary. Endocrinology 114 851-854.

Vale W, Spiess J, Rivier C \& Rivier J 1981 Characterization of a 41-residue ovine hypothalamic peptide that stimulates secretion of corticotropin and beta-endorphin. Science 213 1394-1397.

Vindrola O \& Lindberg I 1992 Biosynthesis of the prohormone convertase mPC1 in AtT-20 cells. Molecular Endocrinology 6 1088-1094.

Westphal CH, Muller L, Zhou A, Zhu X, Bonner-Weir S, Schambelan M, Steiner DF, Lindberg I \& Leder P 1999 The neuroendocrine protein 7B2 is required for peptide hormone processing in vivo and provides a novel mechanism for pituitary Cushing's disease. Cell 96 689-700.

Zhu X \& Lindberg I 1995 7B2 facilitates the maturation of proPC2 in neuroendocrine cells and is required for the expression of enzymatic activity. Journal of Cell Biology 129 1641-1650.

Received in final form 30 November 2006

Accepted 6 December 2006

Made available online as an Accepted Preprint 27 December 2006 